Tohoku J. Exp. Med., 2006, 209, 1-6

\title{
Clinical Features of Cauda Equina Tumors Requiring Surgical Treatment
}

\author{
Yoichi Shimada, Naohisa Miyakoshi, ${ }^{1}$ Yuji Kasukawa, ${ }^{1}$ Michio Hongo, ${ }^{1}$ \\ SHigeru ANDO ${ }^{1}$ and EiJi ITOI ${ }^{1}$ \\ Rehabilitation Division, Akita University Hospital, Akita, Japan, and \\ ${ }^{I}$ Department of Orthopedic Surgery, Akita University School of Medicine, Akita, \\ Japan
}

Shimada, Y., Miyakoshi, N., Kasukawa, Y., Hongo, M., Ando, S. and Itoi, E. Clinical Features of Cauda Equina Tumors Requiring Surgical Treatment. Tohoku J. Exp. Med., 2006, 209 (1), 1-6 — In this study, we evaluated the clinical features of cauda equina tumors requiring surgical treatment. Medical records of 28 patients with cauda equina tumors (13 men and 15 women) undergoing surgical treatment were retrospectively reviewed. The majority of histological diagnoses indicated schwannoma (23 cases, 82\%), and the remaining 5 indicated ependymoma, neurofibroma, meningioma, and ganglioneuroblastoma. In $86 \%$ of the cases, the initial symptom was pain in the lower back and/or lower extremities. Preoperatively, half of the patients had symmetrical pain in the lower back or lower extremities, severe pain in the supine position, or pain that was increased by coughing. One third of the patients needed morphine to control nocturnal pain. Tumor size, as determined by magnetic resonance imaging (MRI), correlated with preoperative symptom duration $(r=0.66, p<0.001)$. These findings indicate that symmetrical lower back pain and/or pain that radiates to both lower extremities and increases in the supine position are characteristic of cauda equina tumors. The correlation between symptom duration and tumor size indicates that earlier diagnosis of this tumor is necessary. Earlier diagnosis based on these characteristic symptoms should make use of further examinations such as MRI. — cauda equina tumors; clinical features; surgical treatment

(C) 2006 Tohoku University Medical Press

Tumors of the cauda equina are rare, and account for only $6 \%$ of spinal tumors (Love 1944; Norstrom et al. 1961; Rewcastle and Berry 1964; Fearnside and Adams 1987), but they are an important cause of lower back pain and/or sciatic syndrome. The results of surgery for cauda equina tumors depend not only on the histological diagnosis but also on the tumor size, and patients with large tumors may have irreversible neurological changes. The importance of early diagnosis and treatment for cauda equina tumors is widely recognized (Fearnside and Adams 1987). Magnetic resonance imaging (MRI) is essential for proper diagnosis of cauda equina tumors. In clinical settings, it is difficult to differentiate cauda equina tumors from other conditions such as prolapsed intervertebral discs based only on symptoms. Cauda equina tumors are sometimes overlooked or misdiagnosed for long periods of time. Clinical manifestations or other findings

Received December 21, 2005; revision accepted for publication March 1, 2006.

Correspondence: Yoichi Shimada, M.D., Rehabilitation Division, Akita University Hospital, 1-1-1 Hondo, Akita 010-8543, Japan.

e-mail: yshimada@med.akita-u.ac.jp 
that suggest a cauda equina tumor should be noted before imaging diagnosis. The purpose of the present study was to clarify the characteristics of clinical symptoms of cauda equina tumors, to enable earlier diagnosis.

\section{Materials ANd Methods}

We retrospectively reviewed the medical records of 28 consecutive patients ( 13 men and 15 women) who underwent surgical treatment for cauda equina tumors at our institutions from 1991 to 2003 . The mean age at surgery was 50 years (range, 5 to 84 years). All patients underwent complete tumor extirpation via laminectomy, and all diagnoses were histologically confirmed. Preoperative clinical records (including neurologic status and symptoms) and imaging records (including radiographs and MRI) were available for all patients. We evaluated symptoms reported at onset, symptoms reported immediately before surgery, preoperative symptom duration, and tumor size (measured by MRI). The tumor size was determined from the tumor length in the cranialcaudal and horizontal directions. We evaluated correlation between tumor size and symptom duration. Because the distribution of tumor size in the horizontal direction was small, only the cranial-caudal tumor size was used to evaluate correlation. Linear regression analysis was used to evaluate correlation between tumor size in the cranialcaudal direction and preoperative symptom duration. $P$ values of $<0.05$ were considered to indicate significance.

The protocol for this study was approved by the Ethics Committee at Akita University School of Medicine (Akita, Japan).

\section{Results}

Characteristics of the patient population and tumor types

The mean duration of symptoms was 22 months (range, 1-93 months). Schwannomas accounted for $82 \%$ of the tumors (23/28 cases), and 3 of the 23 cases of schwannoma (13\%) were multiple. The remaining 5 cases comprised 2 cases of ependymoma (7\%) and 1 case each of neurofibroma, meningioma, and ganglioneuroblastoma. Preoperatively, 4 tumors (3 schwannomas and 1 ependymoma; $14 \%$ of cases) exhibited mobility on myelography or MRI. Four tumors (3 schwannomas and 1 neurofibroma; $14 \%$ of cases) were of the dumbbell type (Table 1).

The localizations of the tumors are shown in Fig. 1. Four tumors were localized between levels T12 and L1 (14\%). Fourteen tumors were localized between levels L1 and L3, including 4 tumors that extended to level L4 or L5 (50\%). The remaining 10 tumors were localized below level L3 (36\%).

\section{Clinical symptoms at onset}

The chief complaints at onset of symptoms are shown in Table 2. Twenty-four patients (86\%) reported pain: lower back and/or buttock pain alone (10 cases; $36 \%$ ); lower back and/or buttock pain radiating to the legs (8 cases; 29\%); and leg pain alone (unilateral or bilateral; 6 cases; $21 \%$ ). The symptoms of the remaining 4 cases were numbness of the legs (3 cases, 11\%) and motor weakness of the legs ( 1 case, $4 \%$ ).

TABLE 1. Characteristics of the sample population

\begin{tabular}{lcccccccc}
\hline & $n$ & $\%$ & $\begin{array}{c}\text { Median } \\
\text { age } \\
\text { (years) }\end{array}$ & $\begin{array}{c}\text { Average duration } \\
\text { of symptom } \\
\text { (months) }\end{array}$ & Multiple & Mobility & Dumbbell & M:F \\
\hline All & 28 & & 50 & 22 & 3 & 4 & 4 & $15: 13$ \\
Schwannoma & 23 & 82 & 54 & 23 & 3 & 3 & 3 & $12: 11$ \\
Ependymoma & 2 & 7 & 27 & 21 & - & 1 & - & $0: 2$ \\
Meningioma & 1 & 4 & 37 & 10 & - & - & - & M \\
Neurofibroma & 1 & 4 & 38 & 3 & - & - & 1 & M \\
Ganglioneuroblastoma & 1 & 4 & 36 & 11 & - & - & - & F \\
\hline
\end{tabular}




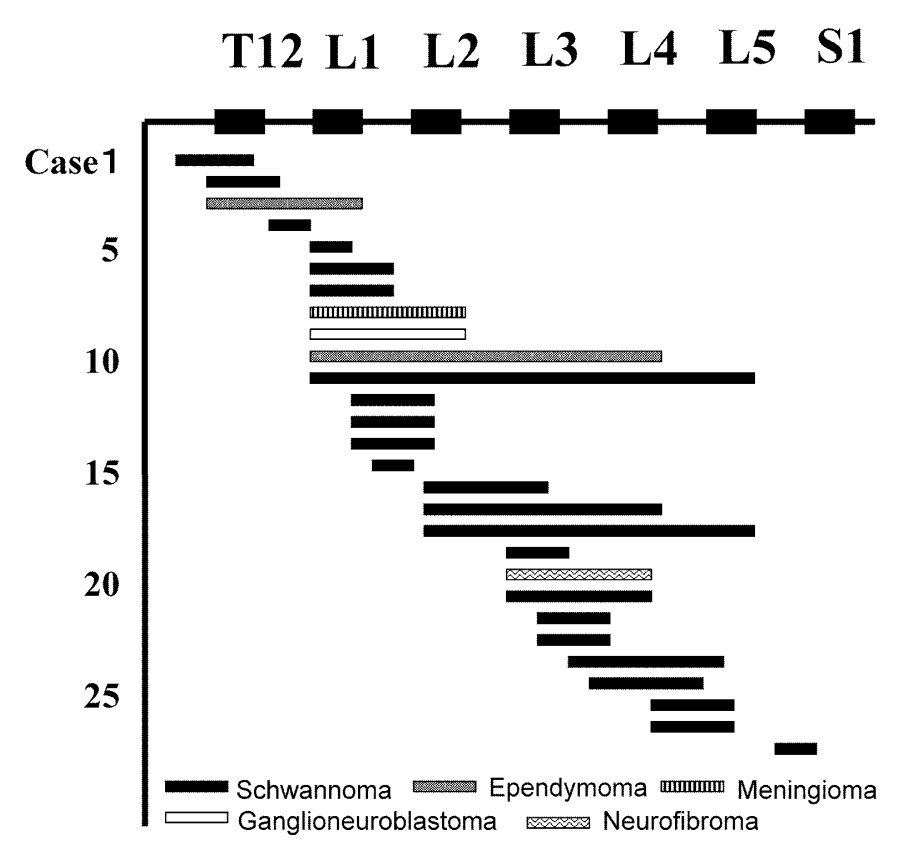

Fig. 1. Distribution of cauda equina tumors undergoing surgical treatment.

The bars show the sizes and locations (spinal level) of tumors. Half of tumors were located between L1 and L3 level.

TABLE 2. Relationship between clinical presentation at onset of symptoms and tumor histology

\begin{tabular}{lcccccc}
\hline & $n$ & $\begin{array}{c}\text { Low back pain } \\
(\mathrm{LBP})(\%)\end{array}$ & $\begin{array}{c}\text { Lower extremity } \\
(\mathrm{L} / \mathrm{E}) \text { pain }(\%)\end{array}$ & $\begin{array}{c}\text { LBP and L/E } \\
\text { pain }(\%)\end{array}$ & $\begin{array}{c}\text { Numbness of } \\
\text { L/E (\%) }\end{array}$ & $\begin{array}{c}\text { Motor weakness } \\
\text { of L/E }(\%)\end{array}$ \\
\hline All & 28 & $10(36)$ & $8(29)$ & $6(21)$ & $3(11)$ & $1(4)$ \\
Schwannoma & 23 & 9 & 6 & 4 & 3 & 1 \\
Ependymoma & 2 & 1 & 1 & - & - & - \\
Meningioma & 1 & - & - & 1 & - & - \\
Neurofibroma & 1 & - & - & 1 & - & - \\
Ganglioneuroblastoma & 1 & - & 1 & - & - & - \\
\hline
\end{tabular}

\section{Features of pain and clinical findings}

The number of patients who reported pain increased to 26 by the time of the operation. Table 3 shows the characteristics of cauda equina tumor symptoms that are associated with early diagnosis. More than half of the patients (14 cases, 54\%) complained of bilateral lower back or leg pain. In 13 patients (50\%), pain increased in the supine position or when the patient lay down. In 12 patients (46\%), the pain was increased by coughing or sneezing. Seven patients $(27 \%)$ used morphine to control pain or reported nocturnal pain.
The majority of the patients ( 21 cases, $75 \%$ ) exhibited hyper- or hyporeflexia on examination of the deep tendon reflexes in the lower extremities. In 16 cases $(57 \%)$, motor weakness ( 8 cases) or sensory disturbance ( 8 cases) was observed. Furthermore, bladder-urinary dysfunction and decreased straight leg raising (SLR) ability were observed in 9 cases (32\%) and 11 cases (39\%), respectively. In addition to these clinical physiological findings, plain X-rays of 11 patients (39\%) revealed abnormalities such as erosion of the pedicles, increased interpedicular distance, scoliosis of the lumbar spine, or spondylolisthesis (Table 4). 
TABLE 3. Characteristics of pain during treatment

\begin{tabular}{lcccccc}
\hline & $n$ & $\begin{array}{c}\text { Bilateral } \\
(\%)\end{array}$ & $\begin{array}{c}\text { Increased in } \\
\text { supine position } \\
\text { or by lying } \\
\text { down (\%) }\end{array}$ & $\begin{array}{c}\text { Increased by } \\
\text { coughing or } \\
\text { sneezing } \\
(\%)\end{array}$ & $\begin{array}{c}\text { Increased at } \\
\text { night } \\
(\%)\end{array}$ & $\begin{array}{c}\text { Use of } \\
\text { morphine } \\
(\%)\end{array}$ \\
\hline All & 26 & $14(54)$ & $13(50)$ & $12(46)$ & $7(27)$ & $7(27)$ \\
Schwannoma & 21 & 11 & 10 & 9 & 5 & 6 \\
Ependymoma & 2 & 0 & 2 & 2 & 1 & 1 \\
Meningioma & 1 & 1 & 0 & 1 & 0 & 0 \\
Neurofibroma & 1 & 1 & 0 & 0 & 0 & 0 \\
Ganglioneuroblastoma & 1 & 1 & 1 & 0 & 1 & 0 \\
\hline
\end{tabular}

TABLE 4. Other clinical, neurological, and image findings for patients during treatment

\begin{tabular}{lccccccc}
\hline & $n$ & $\begin{array}{c}\text { Abnormality } \\
\text { of deep } \\
\text { tendon } \\
\text { reflexes } \\
(\%)\end{array}$ & $\begin{array}{c}\text { Motor } \\
\text { weakness } \\
(\%)\end{array}$ & $\begin{array}{c}\text { Sensory } \\
\text { disturbance } \\
(\%)\end{array}$ & $\begin{array}{c}\text { Bladder-urinary } \\
\text { dysfunction } \\
(\%)\end{array}$ & $\begin{array}{c}\text { Decrease in } \\
\text { SLRT (\%) }\end{array}$ & $\begin{array}{c}\text { Abnormal } \\
\text { radiographs } \\
(\%)\end{array}$ \\
\hline All & 28 & $21(75)$ & $8(29)$ & $8(29)$ & $9(32)$ & $11(39)$ & $11(39)$ \\
Schwannoma & 23 & 18 & 6 & 6 & 9 & 9 & 7 \\
Ependymoma & 2 & 1 & 1 & 1 & 0 & 2 & 1 \\
Meningioma & 1 & 1 & 0 & 0 & 0 & 0 & 0 \\
Neurofibroma & 1 & 1 & 0 & 1 & 0 & 0 & 1 \\
Ganglioneuroblastoma & 1 & 0 & 1 & 0 & 0 & 0 & 1 \\
\hline
\end{tabular}

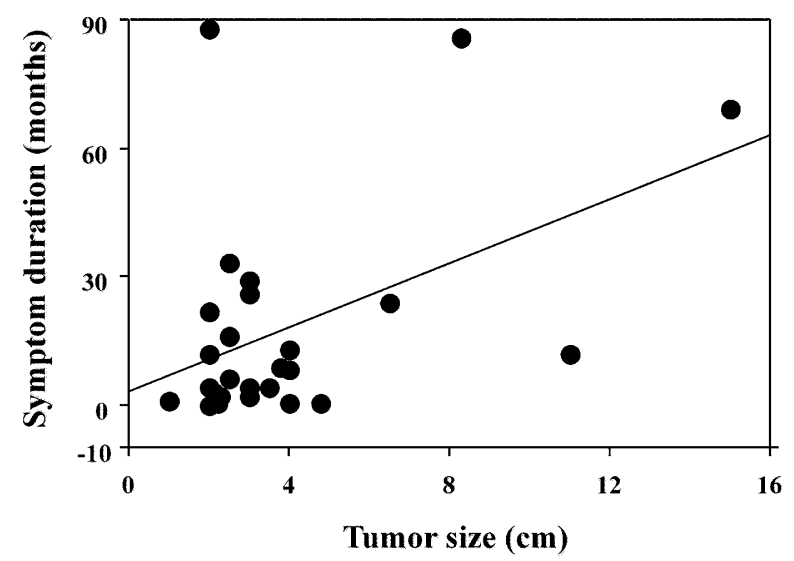

Fig. 2. Correlation between tumor size and symptom duration.

Moderate, significant correlation between tumor size in cranial-caudal direction measured by MRI and preoperative symptom duration $(n=28, r=0.46, p<0.01)$.
Correlation between tumor size and symptom duration

We used linear regression to analyze data from all 28 patients for correlation between tumor size (cranial-caudal direction) and duration of symptoms (from onset to diagnosis of tumor with MRI). We found a moderate correlation between tumor size and symptom duration $(n=28, r=0.46$, $p<0.01$ ) (Fig. 2).

\section{DiscuSSION}

In the present study, we retrospectively reviewed clinical symptoms and radiographic findings of 28 patients with cauda equina tumors requiring surgical treatment in our institutions. The background factors and physical examination findings of the patients were examined to clarify the characteristics of symptoms of cauda equina tumors. MRI findings indicating tumor size were also reviewed to assess correlation between tumor 
size and symptom duration.

The mean duration of symptoms from onset to tumor diagnosis was 22 months, and there were no large differences in symptom duration among histotypes. In previous studies, the mean duration of symptoms of cauda equina tumors from onset to diagnosis ranged from 2 to 6 years (Love 1944; Hanakita et al. 1992; Cervoni et al. 1995). In all reported series of cauda equina tumors, clinical histories were long, probably due to the nature of the clinical symptoms (typically pain without neurological signs). In the present series, the first patient presented to our hospital in 1991, and all of the present tumors were diagnosed by MRI. Several authors have recommended that MRI be the first examination performed in cases of suspected cauda equina tumors, and have noted that MRI plays an important role in early identification of cauda equina tumors (Mathew and Todd 1993; Parenti et al. 1993).

In the present study, there was a moderate correlation between tumor size and symptom duration: tumor size (measured with MRI) increased with increasing symptom duration. There is no available data on the natural course of change in cauda equina tumor size. In 1 patient in the present series, who was followed after surgery for multiple neurinoma, a small residual tumor remained the same size for 5 years after surgery. Furthermore, several reports have described cases of remission and relapse of cauda equina tumors (Nayernouri 1985; Hanakita et al. 1992). Therefore, symptoms caused by cauda equina tumors may depend not only on tumor size but also on some trigger of tumor relapse. However, Parenti et al. (1993) reported that early recognition of cauda equina tumors, before they give rise to irreversible neurological sequelae, remains the most important challenge. If a small cauda equina tumor without clinical symptoms is detected, it should be carefully observed to determine whether it subsequently gives rise to symptoms. Based on the above-described findings, we believe that early diagnosis is important for reducing surgical invasion and aiding adequate recovery from symptoms.

In the present series, to find symptom char- acteristics that can aid early diagnosis of cauda equina tumors, we reviewed symptoms at onset and characteristics of pain symptoms. In $86 \%$ of the present cases, the symptom at onset was pain, without sensory change or motor weakness. This finding is consistent with previous reports, in which the initial symptom of $45 \%$ to $95 \%$ of cases was back pain alone or back pain associated with sciatic pain (Ker and Jones 1985; Hanakita et al. 1992; Mathew and Todd 1993; Parenti et al. 1993; Cervoni et al. 1995). Most investigators have emphasized that pain alone without neurological deficit is associated with long duration of symptoms until diagnosis or treatment. In the present series, a patient with medial knee pain had been treated with injection of hyaluronic acid for osteoarthritis of the knee joint. It was difficult to distinguish pain originating in the knee from pain due to a cauda equina tumor at level L3 involving the L3 nerve root, but the pain due to the tumor was increased by coughing or sneezing.

In the present study, to distinguish the pain of a cauda equina tumor from pain due to lumbar disc herniation or osteoarthritis, we examined the characteristics of pain. Several authors have described the characteristics of pain associated with cauda equina tumors. HogenEsch and Staal (1988) reported that the initial and most prominent symptom of cauda equina tumors was pain that was localized to the lower back and/or radiated to the legs. Furthermore, several other authors have reported that pain associated with cauda equina tumors becomes progressively more severe in later stages and changes from unilateral to bilateral (Cervoni et al. 1994), and that the pain increases at night or is worsened by coughing, sneezing, and straining (Ker and Jones 1985; HogenEsch and Staal 1988). Based on previous reports and the present review, we can classify pain of cauda equina tumors into the following categories: 1) bilateral pain in the lower back and/ or radiating to the leg; 2) pain increased by lying down or the supine position; 3) pain increased by sneezing and/or coughing; and 4) pain that increases at night. 


\section{Conclusions}

In the present study, we examined the characteristics of symptoms of cauda equina tumors and the importance of early diagnosis. At symptom onset, it is difficult to distinguish pain due to a cauda equina tumor from pain due to lumbar disc herniation. However, the pain caused by cauda equina tumors has features that can be used for early diagnosis, even in the early phase of symptoms. If pain with these features is observed, MRI examination should be performed as early as possible to check for a cauda equina tumor.

\section{References}

Cervoni, L., Celli, P., Scarpinati, M. \& Cantore, G. (1994) Neurinomas of the cauda equina clinical analysis of 40 surgical cases. Acta Neurochir., 127, 199-202.

Cervoni, L., Celli, P., Cantore, G. \& Fortuna, A. (1995) Intradural tumors of the cauda equina: a single institution review of clinical characteristics. Clin. Neurol. Neurosurg., 97, 8-12.
Fearnside, M.R. \& Adams, C.B.T. (1978) Tumors of the cauda equina. J. Neurol. Neurosurg. Psychiatry, 41, 24-31.

Hanakita, J., Suwa, H., Nagayasu, S., Nishi, S., Iihara, K. \& Sakaida, H. (1992) Clinical features of intradural neurinomas in the cauda equina and around the conus medullaris. Neurochirurgia, 35, 145-149.

HogenEsch, R.I. \& Staal, M.J. (1988) Tumors of the cauda equina: the importance of an early diagnosis. Clin. Neurol. Neurosurg., 90, 343-348.

Ker, N.B. \& Jones, C.B. (1985) Tumors of the cauda equine. The problem of differential diagnosis. J. Bone Joint Surg. $B r ., 67,358-362$.

Love, J.G. (1944) Differential diagnosis of intraspinal tumors and protruded intervertebral disks and their surgical treatment. J. Neurosurg., 1, 275-290.

Mathew, P. \& Todd, N.V. (1993) Intradural conus and cauda equina tumors: a retrospective review of presentation, diagnosis and early outcome. J. Neurol. Neurosurg. Psychiatry, 56, 69-74.

Nayernouri, T. (1985) Neurilemomas of the cauda equina presenting as prolapsed lumbar intervertebral disks. Surg. Neurol., 23, 187-188.

Norstrom, C.W., Kernoham, J.W. \& Love, J.G. (1961) One hundred primary caudal tumors. JAMA, 178, 1071-1077.

Parenti, G., Fiori, L., Marconi, F. \& Tusini, G. (1993) Primary cauda equina tumors. J. Neurosurg. Sci., 37, 149-156.

Rewcastle, N.B. \& Berry, K. (1964) Neoplasms of the lower spinal canal. Neurology, 14, 608-615. 